RESEARCH Note

\title{
Comparative statistical analysis of incidental dolphin mortality, during fishing trips of the Mexican purse seine tuna fishery in the Eastern Pacific Ocean recorded by two scientific observer programs
}

\author{
Análisis estadístico comparativo de la mortalidad incidental de delfines en viajes de \\ pesca de embarcaciones atuneras mexicanas en el Pacífico oriental, registrada por dos
} programas de observadores científicos

\section{Michel J. Dreyfus-Leon ${ }^{1 *}$ and Elena Solana-Arellano²}

\author{
'Instituto Nacional de Pesca y Acuacultura (INAPESCA), Carretera Tijuana-Ensenada Km. 97.5, Parque Industrial FONDEPORT, El \\ Sauzal de Rodríguez, C.P. 22760, Ensenada, B.C. México \\ ${ }^{2}$ Centro de Investigación Científica y Educación Superior de Ensenada (CICESE), Carretera Ensenada - Tijuana No. 3918, Zona Playitas \\ CP. 22860, Ensenada, B.C., México \\ *Corresponding author: michel.dreyfus@inapesca.gob.mx
}

\begin{abstract}
Scientific observer programs in fisheries are being deployed worldwide in order to obtain robust data for fishery studies, and in relation to its interaction with target and bycatch species. A comparison between two observer programs in Mexican purse seine tuna fishery in the Eastern Pacific Ocean is performed considering the incidental mortality per trip as a metric recorded by both observers programs from 1999 to 2016. A Bayesian t-test approximation was used for the comparison between the two methods since, due to its probabilistic nature reduces uncertainty. The analysis showed a very low probability of differences for the estimated bycatch rate between both programs.
\end{abstract}

Key words: Tuna fishery, incidental dolphin mortality, scientific observer program, Bayesian statistical comparison

\section{INTRODUCTION}

The assessment of the impact of fisheries on marine ecosystems is complicated because historically emphasis or attention has been placed on obtaining reliable statistics through logbooks in order to report data of fishing effort, location and target catch magnitude. The logbooks, are generally "filled" by the captain of each vessel, whom is not trained to take biological information and has other priorities during fishing operations.

Incidental catch has traditionally not been addressed but the decline of several populations of marine vertebrate has increased the focus on this component of other fishery impacts (Lewinson et al. 2004).

In order to improve the quality and/or complete this information, several observer programs have been implemented all over the world. Observer programs provide high-quality bycatch data (Lewinson et al. 2004), especially if these observers have adequate training and academic background to identify species interactions with the fishery and the preparation to appropriately quantify the amounts of incidental mortality.

Due to incidental dolphin mortality in the USA tuna fishery fleet in the Eastern Pacific, the National Marine Fisheries Service of the USA, initiated an observer program in 1966 (Chivers 2018). Starting in 1992 and under the "La Jolla Agreement" the observer program reached a $100 \%$ coverage for vessels above 363 tons of carrying capacity (IATTC 1998)'. The "La Jolla Agreement" was signed by many members of the Inter American Tropical Tuna Commission (IATTC), which is a regional organization in charge of tuna management in the eastern Pacific Ocean. One of the main goals was to quantify instead of estimate dolphin mortality and also to keep track of fishing 
operations as well as monitoring the implementation of measures directed to the reduction of the incidental mortality of dolphins in the eastern Pacific Ocean.

Later, in 1999, a binding agreement called "the Agreement of the International Dolphin Conservation Program", AIDCP was signed and a series of rules and actions, were established in order to fulfill the programs objectives (IATTC 2017) ${ }^{2}$. This document sets down the requirements and training that the scientific observers must satisfy to comply with the AIDCP, in the case of Mexico, a national observer program [Programa Nacional de Aprovechamiento del Atún y Protección del Delfín, (PNAAPD)] was established since 1992 in conjunction with the observer program administered by the secretariat of the AIDCP (IATTC program). From the beginning, all the activities of the PNAAPD have sought to have the same quality as the IATTC program. This is reflected by the fact that the first observers of the PNAAPD were trained by the "National Marine Fisheries Service" of the USA, the potential national observers are selected from a pool of people having fisheries or biology background and national training courses have the same material and level that the training for IATTC-AIDCP potential observers. Since the PNAAPD was the first national program within the AIDCP, their model has been followed by other countries. Therefore, from 2000 to 2008, the International Review Panel, a subsidiary group from AIDCP, reviewed, analyzed and statistically compared the results of the observer's programs in order to record possible infractions of the AIDCP. After concluding that all programs achieved similar performances the comparison among programs were canceled (IATTC 2008) $)^{3}$

The purpose of this work was to statistically analyze both observer programs IATTC and PNAAPD covering the Mexican purse seine fishery 10 year after the abovementioned comparison halted. Therefore, data from 1992 were used, -the year of the beginning of the $100 \%$ coverageuntil 2016.

\section{MATERIALS AND METHOdS}

The general procedure to select observers from each program to cover all fishing trips is as follows: From the pool of available observers, one is randomly selected avoiding for as much time as possible that this observer gets onboard a vessel he already reported in a previous trip; moreover, each vessel is covered alternately on each program on a trip by trip basis. In this study the fishing trip was considered the unit of analysis, this because a particular observer covers the trip fishing activities and the data of a particular fishing trip are linked to the onboard observer. Since the main objective was to compare the performance of these programs in the Mexican purse seine fishery in the eastern Pacific Ocean hereinafter called $P A$ and $P B$, the mortality of fishing dolphins (of several species) was used as a measure.

\section{Statistical METHOdS}

In order to seek for differences between means on dolphin incidental mortality (IM) and since both programs did not have the same number of trips per year, mean trip incidental mortality per year was used as dependent variable for both programs, this with the aim of unbiased the annual IM of the two observers programs. Normality on both series was confirmed ( $P>0.27$ ) using the Shapiro-Wilk test (Zar 1999). Therefore, a parametric t-test between both programs was performed using R platform (R Core Team 2017).

Since data is composed by a set of individual's observations, intersubjectivity could introduce uncertainty. Therefore, a more robust approach has been followed using a maximum likelihood approximation by means of a Bayesian t-test statistic which due to its probabilistic nature has less error and reduces the uncertainty (Boldstad 2007). The Bayesian hypothesis for the posterior difference of means was:

$$
\begin{aligned}
& H_{0}=\mu_{p A}-\mu_{p B}=0 \\
& H_{a}=\mu_{p A}-\mu_{p B} \neq 0
\end{aligned}
$$

And a priori normal was chosen and $\alpha=0.05$. The Bayesian approach was performed using the R platform (R Core Team 2017).

\footnotetext{
${ }^{2}$ AIDCP (last amended Oct 2017). Agreement on the International Dolphin Conservation Program (amended ${ }^{1}$ ). Inter-American Tropical Tuna Commission (IATTC). <http://www.iattc.org/PDFFiles/AIDCP/_English/AIDCP-amended-Oct-2017.pdf>

${ }^{3}$ Agreement on the international dolphin conservation program. $20^{\text {th }}$ meeting of the parties. La Jolla California (USA). 4 November 2008. Provisional agenda <https://www.iattc.org/Meetings/Meetings2008/IATTC-79/AIDCP-20/Agendas/_English/MOP-20-AGN_20th\%20Meeting\%20of\%20the\%20 Parties\%20to\%20the\%20AIDCP.pdf >
} 


\section{RESULTS AND DISCUSSION}

Similar basic statistics for both programs are shown in Figure 1. The parametric frequentist t-test showed no significant differences between both programs $(\mathrm{t}=1.16$, $\mathrm{df}=34$ and $P=0.25$ ); the mean trip dolphin mortality per year was estimated of $3.37 \pm 0.84$ for $P A$ and $3.08 \pm 0.67$ for $P B$. Figure 2, show a discrepancy between programs for the means dolphin mortality per year specially in 2000. Nevertheless, it has been shown that most of the time frequentist null hypothesis testing is overestimated or misunderstood in favor of the null hypothesis (Gerrodete 2001). Therefore, the frequentist approach was strengthened with a t-test of Independent Bayesian samples with the posterior mean differences of 0.31 and a $95 \%$ credibility interval of $[-0.256,0.925]$ showed that since $H o$ of equation (1) is within the interval is still credible therefore it is concluded that $H a$ is not credible. Moreover, the Bayes factor $B=P\left(H_{0}\right) / P\left(H_{\alpha}\right)=1.09$ implies that there was the same probability for $\mathrm{Ho}$ than for $\mathrm{Ha}$ with an error of $1.189 \mathrm{e}-4$, therefore the equality for incidental mortality mean for both programs is still credible.

Even though Figure 1 shows that both programs presented several outliers, the statistical analysis found no significant differences between programs. This could mean that both programs are operating with the same protocol and that the observer's program information is standardized, robust and comparable. Program A has generally higher total mortality per year than Program B, this could suggest that the national program could have a lower standard but none statistical analysis has demonstrated a difference between programs. The cause of the above difference might be due

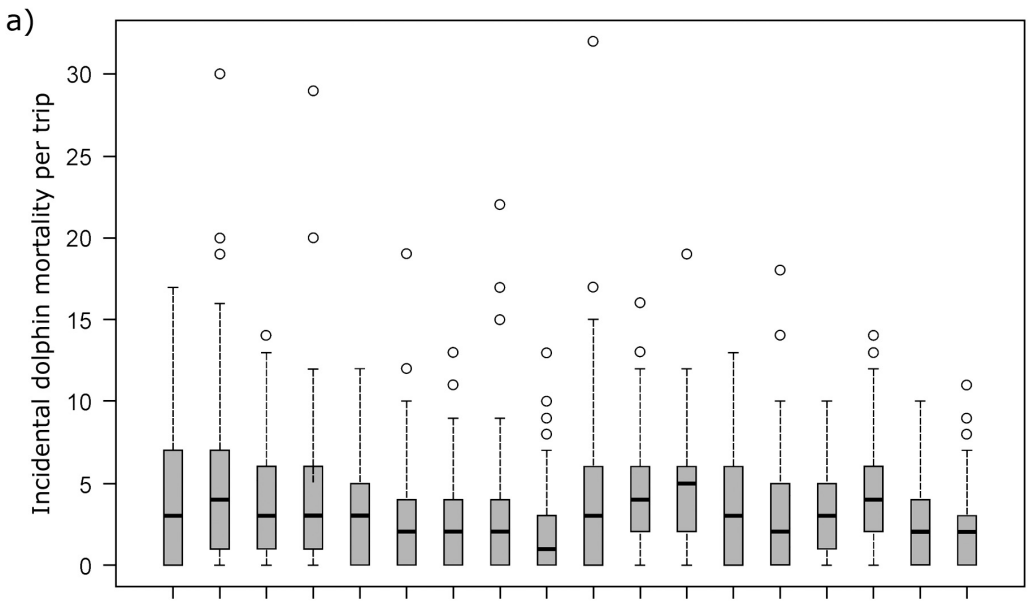

b)

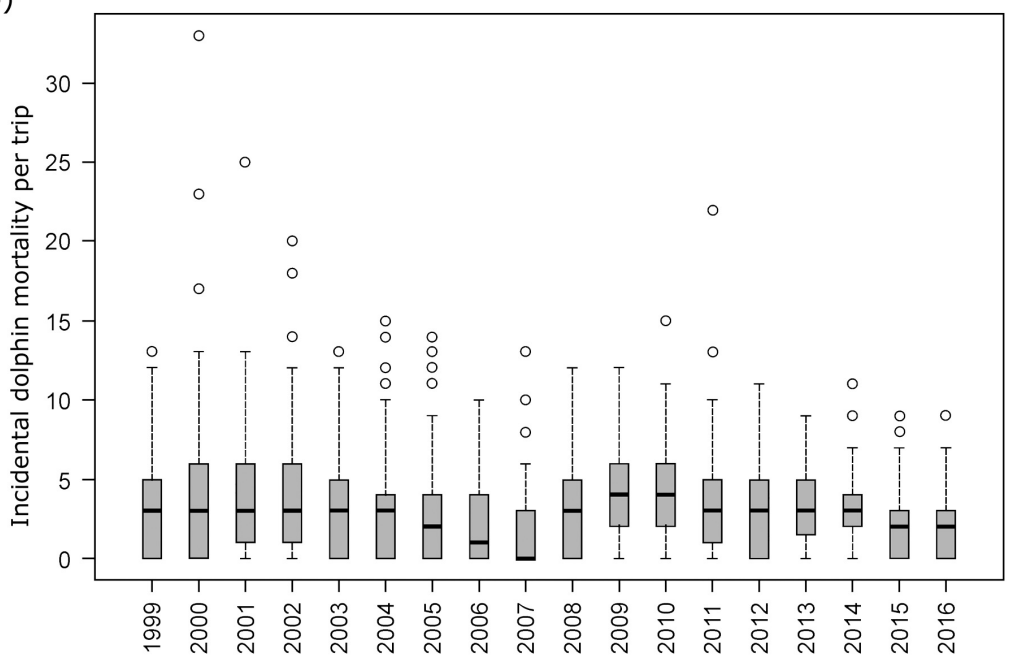

Figure 1. Description of incidental dolphin mortality per trip, with mean and standard deviation per year per program, dots represent possible outliers. a) IATTC program, b) PNAAPD Program / Descripción de la mortalidad incidental de delfines por viaje, se presenta la media y desviación estándar por año por programa. Los puntos representan posibles datos extremos. a) Programa IATTC, b) Programa PNAAPD 


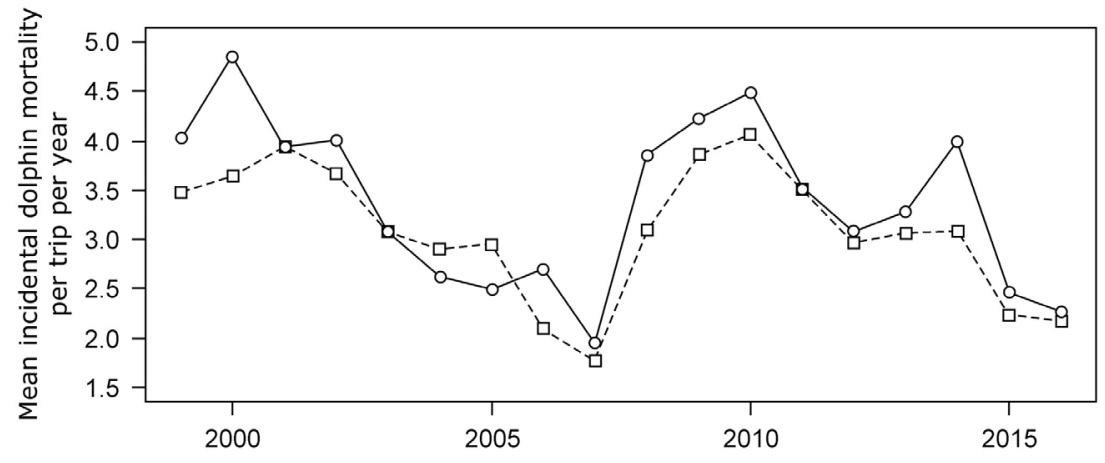

Figure 2. Trends in the mean of incidental dolphin mortality per trip per year for each program. Continuous lines represent IATTC program and dashes line PNAAPD Program / Tendencia de medias de mortalidad incidental de delfines por viaje por año para cada programa. La línea continua representa el Programa IATTC y la línea punteada el programa PNAAPD

to difference in trip coverage since PA has more covered trips than the national program. For this reason, this analysis was considered based on the mean per trip, eliminating the problem of coverage differences between both programs. In general, there are more trips covered by the international observer program because it was stipulated that it should cover at least $50 \%$ of the trips each year (IATTC 2008) ${ }^{3}$.

Through a simulation model of the Mexican observer's program for dolphin mortality in the eastern Pacific tuna purse seine fishery Echavarria-Heras et al. $(2000)^{4}$, tested the consistency of observer data and inferred the optimal coverage level to reduce dolphin mortality. After over a quarter of a century with a $100 \%$ coverage, information provided by observers has been of great importance to quantify the magnitude and composition of incidental mortality on purse-seine fishing in the eastern Pacific Ocean. Evaluations of fisher performance and monitoring conservation measures adopted in IATTC have also provided invaluable data related to the interaction of fishery with other species as well as biological information and distribution of those same species. It is generally considered that small observer coverage sample, if unbiased, would give reasonable estimates of bycatch mortality for common species but a large coverage would be needed for rare species (Amandè et al. 2010). Although lower coverage could have been an option, $100 \%$ coverage was necessary to have more exact values of mortality and avoid the possibility of fisher modifying behavior due to the observer presence effect that results from changes in fishing practice or location when observers are present (Benoit \& Allard 2009).

Therefore, observers programs are a necessary tool for the expansion to the ecosystem based approach to fishery management, changing the monitoring and management of individual populations (target species) taking into account other potential effects at the ecosystem level (Gilman et al. 2017).

\section{AKNOWLEDGEMENTS}

The authors are thankful to Juan Manuel Galaviz López for the help in the statistical analysis and figures.

\section{LITERATURE CITED}

Amandè MJ, CE Lennert-Cody, N Bez, M Hall \& AC Chassot. 2010. How much sampling coverage affects bycatch estimates in purse seine fisheries? IOTC-2010WPEB-20: 1-16.

Benoit HP \& J Allard. 2009. Can the data from at-sea observer surveys be used to make general inferences about catch composition and discards? Canadian Journal of Fisheries and Aquatic Sciences 66: 2025-2039.

Boldstad WM. 2007. Introduction to Bayesian statistics, 464 pp. John Wiley \& Sons, Hoboken.

Chivers SJ. 2018. Marine mammal life history: Guide to biological sample collection and data archive. NOAA Technical Memorandum NMFS, NOAA-TM-NMFSSWFSC-594: 1-50. 
Gerrodete T. 2011. Inference without significance: measuring support for hypotheses rather than rejecting them. Marine Ecology 32: 404-418.

Gilman E, M Weijerman \& P Suuronen. 2017. Ecological data from observer programmes underpin ecosystem-based fisheries management. ICES Journal of Marine Science 74(6): 1481-1495.

Lewinson RL, LB Crowder, AJ Reed \& SA Freeman. 2004. Understanding impacts of fisheries bycatch on marine megafauna. Trends in Ecology and Evolution 19(11): 598-604.
R Core Team 2017. R: A Language and Environment for Statistical Computing. R Foundation for Statistical Computing, Vienna. $<$ https://www.R-project.org $>$

Zar JH. 1999. Biostatistical analysis, 662 pp. Prentice Hall, Upper Saddle River.

Received 4 March 2019 and accepted 30 September 2019

Editor: Claudia Bustos D. 